\title{
THE USE OF INTERACTIVE MULTIMEDIA IN LEARNING BASED ON DISRUPTION ERA AT ELEMENTARY SCHOOL
}

\section{Rizki Widyawulandari, Sarwanto, Mintasih Indriayu}

Sebelas Maret University

rwidyawulandari@yahoo.co.id

\section{Article History}

accepted 09/07/2018

approved 01/08/2018

published 17/09/2018

\section{Keywords}

Disruption, Interactive

Multimedia, Learning

\begin{abstract}
The disruption era is defined as the time when so many innovations are emerging, unrecognized by established organizations that they interfere with the activities of the old system's order or even destroy the old system. The world of education must also be ready in the face of this disruption era, especially in the era of increasingly advanced technology. One of the efforts in the development of learning-based disrupted era, especially in primary school is the use of interactive multimedia. With the steps and processes of using the right interactive multimedia, using interactive multimedia as a message media will stimulate the thoughts, feelings, concerns and desires of students so as to encourage more interactive and communicative learning process and can improve the learning experience of students become more concrete. The research method used is qualitative with case study design where researchers collect and analyze data about the use of interactive multimedia in primary school. The results revealed that interactive multimedia is considered important in the effort of IT utilization in learning in disruption era but there are still many teachers who have not realized and apply it.
\end{abstract}

Social, Humanities, and Education Studies (SHEs): Conference Series https://jurnal.uns.ac.id/shes

p-ISSN 2620-9284 e-ISSN 2620-9292 


\section{PENDAHULUAN}

Secara umum, era disruptive diartikan sebagai masa di mana bermunculan banyak sekali inovasi-inovasi yang tidak terlihat, tidak disadari oleh organisasi mapan sehingga mengganggu jalannya aktivitas tatanan sistem lama atau bahkan menghancurkan sistem lama tersebut. Banyak yang menganggap disruption hanya berkaitan dengan teknologi informasi dan komunikasi (ICT) yang marak belakangan ini. Rhenald Kasali seorang guru besar manajemen dalam kompas.com dijelaskan bahwa disruption bukan hanya sekedar fenomena hari ini (today), melainkan fenomena "hari esok" (the future) yang dibawa oleh para pembaharu ke saat ini, hari ini (the present). Distruption sesungguhnya terjadi secara meluas. Mulai dari pemerintahan, ekonomi, hukum, politik, kompetisi bisnis dan juga hubungan-hubungan sosial.

Ada beberapa hal yang penting dalam disruption. Pertama, disruption berakibat penghematan banyak biasa melalui proses bisnis yang menjadi lebih simple. Kedua, ia membuat apapun yang dihasilkannya lebih baik ketimbang yang sebelumnya. Ketiga, disruption berpotensi menciptakan pasar baru, atau membuat mereka yang selama ini ter-eksklusi menjadi ter-inklusi. Keempat, produk/ jasa hasil disruption ini harus lebih mudah diakses atau dijangkau oleh para penggunanya. Kelima, disruption membuat segala sesuatu kini menjadi serba smart. Lebih pintar, lebih menghemat waktu dan lebih akurat.

Kebanyakan kasus-kasus disruption dibahas dalam sektor bisnis. Namun jarang sekali dibahas di sektor pendidikan. Dunia pendidikan juga harus siap dalam menghadapi era disruptive ini khususnya dalam era teknologi yang semakin maju. Pentingnya dalam membangun sistem pendidikan yang lebih adaptif terhadap perubahan globalisasi dan revolusi informasi digital. Yakni sistem pendidikan yang terbuka serta memanusiakan manusia, bukan sistem pendidikan yang menyeragamkan yang dibangun dengan asumsi masa lalu. Sistem ini akan melahirkan sekolah-sekolah masa depan. Sekolah yang menyenangkan, yang memberi ruang tumbuhnya keunikan potensi setiap anak manusia untuk hidup di era digital. Salah satu upaya dalam pengembangan pembelajaran berbasis era disupsi khususnya di sekolah dasar adalah penggunaan multimedia interaktif.

Anitah (2012: 61) mendefinisikan multimedia merupakan penggunaan berbagai jenis media baik secara berurutan maupun simultan untuk menyampaikan informasi atau pesan. Menurut Atmawarni (2011: 23) multimedia interaktif merupakan perpaduan antara berbagai media yang berupa teks, gambar, grafik, sound, animasi, video, interaksi, dll. Yang telah dikemas menjadi file digital, digunakan untuk menyampaikan pesan kepada publik. Berdasarkan pengertian-pengertian di atas, dapat ditarik kesimpulan bahwa multimedia interaktif adalah suatu tampilan multimedia menggunakan komputer yang mengintegrasikan beberapa macam media dimana pengguna dapat belajar secara interaktif karena dilengkapi dengan alat pengontrol yang berfungsi sebagai penghubung dengan program agar pengguna dapat memilih apa yang dikehendaki.

Penggunaan multimedia interaktif merupakan salah satu komponen penting di dalam proses pembelajaran di sekolah karena membantu pencapaian tujuan pembelajaran. Oleh karena itu, penyiapan multimedia interaktif menjadi salah satu tanggung jawab pendidik. Dengan menggunakan alat bantu berupa media pembelajaran yang sifatnya interaktif akan membantu keefektifan proses pembelajaran dan penyampaian pesan serta isi dari pelajaran. Beberapa penelitian menunjukkan bahwa multimedia interaktif telah berhasil memperlihatkan keunggulannya dalam mambantu para guru dan staf pengajar dalam menyampaikan pesan pembelajaran secara cepat dan lebih mudah ditangkap oleh para siswa. Selain itu juga memiliki kekuatan positif dan sinergi yang mampu merubah sikap dan tingkah laku mereka kearah perubahan yang kreatif dan juga dinamis. Hal tersebut sebagaimana disebutkan dalam tujuan Pendidikan Nasional sebagai berikut. 
Pendidikan Nasional berfungsi mengembangkan kemampuan dan membentuk watak serta peradaban bangsa yang bermartabat dalam rangka mencerdaskan kehidupan bangsa, bertujan untuk berkembangnya potensi peserta didik agar menjadi manusia yang beriman dan bertaqwa kepada Tuhan Yang Maha Esa, berakhlak mulia, sehat, berilmu, cakap, kreatif, mandiri, dan menjadi warga Negara yang demokratis serta bertanggungjawab. (UU No. 20 Tahun 2003, Sistem Pendidikan Nasional)

Dalam kurikulum 2013 peran guru dalam aktivitas pembelajaran tidak hanya menyampaikan ilmu pengetahuan akan tetapi menuntut kemampuan guru untuk dapat merancang pembelajaran yang efektif dan bermakna. Berdasarkan hasil wawancara beberapa guru di sekolah dasar, didapatkan temuan bahwa guru dalam menyampaikan materi masih terpaku pada buku ajar yang ada, aktivitas siswa sangat kurang. Mereka hanya mendengarkan penjelasan dari guru tersebut. Di lain pihak, guru akhirnya lebih dominan dalam pembelajaran tersebut dengan metode ceramah dan terpaku pada buku ajar yang digunakan. Guru jarang menggunakan multimedia interaktif dengan alasan minimnya waktu yang diperlukan untuk menyediakan multimedia interaktif saat pembelajaran. Siswa merasa kurang dilibatkan dalam proses pembelajaran sehingga menimbulkan kejenuhan dan kebosanan pada diri mereka. Dampak dari hal itu adalah kurangnya semangat siswa yang berakibat pada rendahnya pemahaman siswa atas materi yang disampaikan oleh guru. Dalam artikel ini penulis bertujuan mengungkapkan penggunaan multimedia interaktif dalam pembelajaran di sekolah dasar khususnya di era disruptif saat ini.

\section{Era Disruptive dalam Dunia Pendidikan}

Menurut Iskandar (2017: 11) disruption adalah suatu proses. la tidak terjadi seketika. Dimulai dari ide, riset, atau eksperimen, lalu proses pembuatan, pengembangan business model. Ketika berhasil, pendatang akan mengembangkan usahanya pada titik pasar terbawah yang diabaikan incumbent, lalu perlahan-lahan menggerus ke atas, ke segment yang sudah dikuasai incumbent. Iskandar (2017: 24) juga mengungkapkan sebab-sebab timbulnya disruption yaitu:

1. Teknologi, khususnya infokom, telah mengubah dunia tempat kita berpijak. Teknologi telah membuat segala produk menjadi jasa, jasa yang serba digital, dan membentuk marketplace baru, platform baru, dengan masyarakat yang sama sekali berbeda.

2. Sejalan dengan itu muncullah generasi baru yang mendukung utama gerakan ini. Mereka tumbuh sebagai kekuatan mayoritas dalam peradaban baru yang menentukan arah masa depan peradaban. Itulah generasi millenials.

3. Kecepatan luar biasa yang lahir dari microprocessor dengan kapasitas ganda setiap 24 bulan menyebabkan teknologi bergerak lebih cepat dan menuntut manusia berpikir dan bertindak lebih cepat lagi.

4. Sejalan dengan gejala distrupted society, muncullah disruptive leader yang dengan kesadaran penuh menciptakan perubahan dan kemajuan melalui cara-cara baru.

5. Kelima, bukan cuma teknologi yang tumbuh, tetapi juga cara mengeksplorasi kemenangan. Manusia-manusia baru mengembangkan model bisnis yang amat disruptive yang mengakibatkan barang dan jasa lebih terjangkau (affordable), lebih mudah terakses (accessible), leboh sederhana, dan lebih merakyat.

6. Teknologi sudak memasuki gelombang ketiga: internet of Things.

Gelombang disruptive dalam pendidikan menurut Iskandar (2017: 34) meliputi:

1. "On demand" jasa-jasa pendidikan dan keterampilan, termasuk ujian

2. "Open source" jasa-jasa pendidikan dan keterampilan.

3. Aplikasi-aplikasi pendidikan yang mobile dan responsive.

4. Kurikulum yang lebih bersifat personal dan "tailor mode".

5. Layanan konten tanpa batas.

6. Platform pendidikan kolaboratif. 
7. Kursus-kursus dan materi-materi gratis secara online.

Cara sekolah dalam menghadapi era disruptive ini adalah perlu adanya pemimpin dengan disruptive mindset. Diperlukan orang-orang untuk membaca tandatanda zaman, yang mampu membaca realitas dan tidak hidup dalam perangkap masa lalu.

\section{Penggunaan Multimedia Interaktif dalam Pembelajaran di Sekolah Dasar}

Adapun pengertian multimedia interaktif secara etimologis multimedia berasal dari kata multi (Bahasa Latin, nouns) yang berarti banyak, bermacam-macam, dan medium (Bahasa Latin) yang berarti sesuatu yang dipakai untuk menyampaikan atau membawa sesuatu. Multimedia sendiri diartikan oleh Smaldino (2011: 200) "multimedia is the sequential or simultaneous of a variety of media in a presentation or self-study program. Computers are often involved in multimedia presentations that incorporate text, audio, and still or animated images". Artinya multimedia adalah serangkaian dari beberapa macam media dalam sebuah presentasi atau program belajar mandiri. Komputer sering digunakan dalam presentasi multimedia yang menyatukan teks, audio, dan gambar diam atau bergerak. Pernyataan ini menunjukkan pengertian multimedia sebagai suatu kesatuan antara berbagai media seperti teks, audio, dan gambar.

Menurut Atmawarni (2011: 23) multimedia interaktif merupakan perpaduan antara berbagai media yang berupa teks, gambar, grafik, sound, animasi, video, interaksi, dll. Yang telah dikemas menjadi file digital, digunakan untuk menyampaikan pesan kepada publik. Berdasarkan pengertian-pengertian di atas, dapat ditarik kesimpulan bahwa multimedia interaktif adalah suatu tampilan multimedia menggunakan komputer yang mengintegrasikan beberapa macam media dimana pengguna dapat belajar secara interaktif karena dilengkapi dengan alat pengontrol yang berfungsi sebagai penghubung dengan program agar pengguna dapat memilih apa yang dikehendaki.

Adapun tahapan penerapan multimedia interaktif dalam pembelajaran menurut Atmawarni (2011: 25) adalah sebagai berikut:

1. Introduction (Pengenalan)
a. Judul Program ( Title Page)
b. Pembelajaran Prompt atau panduan
c. Objektifitas Penyajian
d. Petunjuk
e. Stimulsi Prioritas Pengetahuan (appersepsi berbentuk stimulasi pengetahuan)
f. Inisial Kontrol

2. Presentation of Information (Penyajian Informasi)
a. Mode penyajian atau mode presentasi
b. Panjang teks penyajian
c. Grafik dan animasi
d. Warna dan penggunaannya

3. Question of Response (Pertanyaan dan respon-respon)

4. Judging of Response (Penilaian respon)

Smaldino, dkk (2011: 178) mengungkapkan beberapa hal yang perlu dipertimbangkan dalam memadukan multimedia di dalam kelas, meliputi:

1. Konten harus menyeimbangkan kemampuan mendasar dengan pemikiran tingkat tinggi dan sesuai dengan standar kurikulum.

2. Konten harus memacu dan harus menggiring para siswa ke dalam proses belajar.

3. Konten harus menawarkan pola antardisiplin dan multisensorik bagi pembelajaran dan membantu para siswa menemukan tidak hanya satu jawaban bagi semua masalah, tetapi serangkaian jalan keluar.

4. Konten harus selalu siap kapan saja dan di mana saja dibutuhkan (di ruang kelas, di kunjungan lapangan, di rumah, di masyarakat). 
5. Konten harus membawa para siswa melampaui fakta dan mengajarkan mereka menakar informasi dan menghasilkan kesimpulan yang independen.

6. Para siswa tidak seharusnya sekadar pengguna konten. Mereka seharusnya menjadi pencipta konten dan pembangun pengetahuan.

Smaldino, dkk (2011: 173-174) mengungkapkan keuntungan penggunaan komputer dan multimedia dalam pembelajaran meliputi:

1. Individualisasi. Penggunaan multimedia memungkinkan siswa untuk mengendalikan laju dan urutan pembejaran sehingga memberikan mereka lebih banyak kontrol atas hasil-hasil.

2. Kebutuhan khusus. Penggunaan multimedia efektif untuk siswa khususnya yang beresiko, latar belakang budaya beragam, dan siswa dengan ketidakmampuan yang bisa diakomodasi dan pengajaran berlangsung dalam kecepatan yang semestinya.

3. Pemantauan. Guru dapat menyiapkan mata pelajaran individual untuk seluruh siswa dan memantau perkembangan mereka.

4. Manajemen informasi. Komputer dan multimedia dapat mencakup pengetahuan yang luas dan mengelola seluruh jenis informasi seperti teks, grafis, audio, dan video sehingga lebih banyak informasi bisa disisihkan oleh guru dan siswa.

5. Pengalaman multisensorik. Komputer dan multimedia menyediakan beragam pengalaman belajar yang dapat digunakan dalam berbagai strategi pengajaran dan dapat berada pada tingkat pengajaran, perbaikan, atau pengayaan dasar.

6. Partisipasi pembelajar. Penggunaan komputer dan multimedia mengharuskan siswa untuk terlibat dalam kegiatan sehingga dapat memfokuskan perhatian siswa.

Smaldino, dkk (2011: 174) mengungkapkan keterbatasan penggunaan komputer dan multimedia dalam kegiatan pembelajaran:

1. Hak cipta. Mudahnya aplikasi untuk digandakan tanpa izin membuat penerbit komersial dan wirausahawan swasta enggan membuat dan memasarkannya.

2. Ekspektasi yang tinggi. Para pengguna berharap komputer dan multimedia akan memberikan kemudahan atau bahkan tanpa usaha dalam kegiatan pembelajaran, tetapi pada kenyataannya para pengguna memperoleh keuntungan sesuai dengan investasi mereka.

3. Kompleks. Program-program yang lebih canggih mungkin akan sulit digunakan terutama untuk siswa karena membutuhkan kemampuan untuk menggunakan keterampilan yang kompleks.

4. Kurangnya struktur. Para siswa dengan gaya belajar terstruktur akan sedikit kesusahan terkait dengan seberapa banyak informasi yang harus ditelusuri.

\section{METODE}

Penelitian ini menggunakan metode penelitian kualitatif dengan desain penelitian studi kasus. Lokasi penelitian di SD Muhammadiyah 16 Surakarta, SD Muhammadiyah 1 Surakarta, dan SD Muhammadiyah 24 Surakarta dengan subyek penelitian adalah guru kelas IV. Teknik pengumpulan data menggunakan observasi, wawancara mendalam, dan dokumentasi. Data dianalisis melalui langkah-langkah pengumpulan data, reduksi data, penyajian data, dan verifikasi data. Teknik pemeriksaan keabsahan data dilakukan dengan triangulasi teknik dan triangulasi sumber.

\section{HASIL DAN PEMBAHASAN}

Lokasi penelitian berada di SD swasta Kota Surakarta yang meliputi SD Muhammadiyah 16 Surakarta, SD Muhammadiyah 1 Surakarta, dan SD Muhammadiyah 24 Surakarta. Subyek penelitian adalah guru kelas IV SD swasta kota Surakarta yaitu bapak Darsono, M. Pd., Ibu Rumiyati, S. Pd., dan Ibu Irawati, S. H. Beberapa komponen yang dibahas dalam penelitian meliputi: 


\section{Pemahaman Guru mengenai Era Disruptif}

Bapak Darsono, M. Pd mengungkapkan, "guru belum sepenuhnya paham dan mengetahui mengenai hakikat disrupsi itu apa." Ditambahkan pula oleh lbu Rumiyati, S. Pd., "Dalam dunia pendidikan masih sangat asing mengenai apa itu disrupsi, akan tetapi untuk pengaruh globalisasi guru sudah memahami."

Berdasarkan hasil wawancara dan observasi diketahui bahwa guru memahami akan adanya perkembangan teknologi yang akhirnya masuk dalam dunia pendidikan. Akan tetapi guru kurang memahami bahwa itu merupakan pengaruh dari era disrupsi.

Hal tersebut menegaskan bahwa hakikat dari era disrupsi sendiri tidak disadari oleh pendidik dan sesuai dengan pengertian disrupsi sendiri menurut Iskandar (2017: 11) disruption adalah suatu proses. la tidak terjadi seketika. Dimulai dari ide, riset, atau eksperimen, lalu proses pembuatan, pengembangan business model. Oleh karena ini proses terjadinya disrupsi tidak dapat diungkapkan akan tetapi dampak dari disrupsi tersebut dapat dirasakan dengan adanya kemajuan teknologi dalam dunia pendidikan.

\section{Penggunaan Multimedia Interaktif dalam Pembelajaran}

Dalam pelaksanaan pembelajaran menggunakan multimedia interaktif diperlukan adanya alat bantu berupa laptop, LCD, proyektor, maupun speaker untuk menunjang pembelajaran. Diungkapkan oleh bapak Darsono, M. Pd, "sekolah sudah menyediakan fasilitas tersebut, akan tetapi hanya guru-guru muda yang memanfaatkan perangkat tersebut."

Selain itu pada SD Muhammadiyah 1 Surakarta, wali kelas IV juga mengungkapkan sangat jarang menggunakan media berupa gambar maupun video saat pembelajaran padahal fasilitas sudah tersedia di kelas masing-masing. Berbeda lagi dengan apa yang diungkapkan oleh wali kelas IV SD Muhammadiyah 24 Surakarta, "alat semua sudah tersedia di kelas akan tetapi ada beberapa yang rusak sehingga baik guru maupun siswa tidak dapat memanfaatkannya."

Selain itu diungkapkan pula oleh Bapak Darsono, M. Pd, "Jika guru ingin menggunakan multimedia interaktif pada pelajaran tematik, guru haru menyiapkan sendiri multimedia interaktif tersebut, karena pemerintah tidak menyediakan CD multimedia interaktif tematik."

Ditambakan pula oleh ibu Rumiyati, S. Pd., "Guru hanya bisa memberikan video atau menampilkan gambar akan tetapi itu sangat jarang karena keterbatasan waktu untuk membuat multimedia interaktif."

Berdasarkan hasil wawancara dan observasi didapatkan bahwa untuk perangkat yang digunakan dalam melaksanakan multimedia interaktif sudah disediakan oleh sekolah, akan tetapi guru kurang dapat memanfaatkannya dengan baik. Selain itu, belum ada multimedia interaktif tematik yang disediakan oleh pemerintah sehingga guru harus mencari atau membuat sendiri multimedia interaktif tersebut.

Penggunaan multimedia interaktif dalam pembelajaran tematik masih sangat jarang dilakukan oleh guru melihat segala keterbatasan yang ada. Padahal multimedia interaktif sangat dibutuhkan oleh siswa dalam mendalami materi yang dipelajari. Seperti yang diungkapkan oleh Nandi (2006: 9) bahwa pengalaman siswa akan lebih bertambah dan siswa tidak akan terpaku kepada materi yang ada, akan tetapi dapat memilih sesuai apa yang dibutuhkannya apabila menggunakan multimedia interaktif.

Penggunaan multimedia interaktif dalam pembelajaran tidak akan terlepas dari komputer sebagai media, sehingga pengadaan komputer dan program sebagai media sangat dibutuhkan. Dalam penggunaan multimedia interaktif sangat bergantung pada jenis materi yang akan diberikan terutama materi-materi dalam pembelajaran tematik.

\section{Penggunaan Multimedia Interaktif dalam Pembelajaran di Era Disruptif}

Era disrupsi diartikan sebagai masa di mana bermunculan banyak sekali inovasiinovasi yang tidak terlihat, tidak disadari oleh organisasi mapan sehingga mengganggu jalannya aktivitas tatanan sistem lama atau bahkan menghancurkan sistem lama tersebut. Dunia pendidikan juga harus siap dalam menghadapi era disrupsi ini 
khususnya dalam era teknologi yang semakin maju. Cara sekolah dalam menghadapi era disruptive ini adalah perlu adanya pemimpin dengan disruptive mindset. Diperlukan orang-orang untuk membaca tanda-tanda zaman, yang mampu membaca realitas dan tidak hidup dalam perangkap masa lalu.

Salah satu upaya dalam pengembangan pembelajaran berbasis era disupsi khususnya di sekolah dasar adalah penggunaan multimedia interaktif. Menurut Atmawarni (2011: 23) multimedia interaktif merupakan perpaduan antara berbagai media yang berupa teks, gambar, grafik, sound, animasi, video, interaksi, dll. Yang telah dikemas menjadi file digital, digunakan untuk menyampaikan pesan kepada publik.

Berdasarkan hasil wawancara dan observasi, kesadaran guru akan pengaruh disrupsi yaitu adanya perkembangan teknologi informasi pada sistem pendidikan masih sangat kurang. Guru merasa belum dapat untuk mengikuti era disrupsi dibuktikan dengan masih sedikitnya guru yang menggunakan multimedia interaktif dalam kegiatan pembelajaran.

Colin Rose and Malcolm J. Nicholl (1997) dalam bukunya menyatakan bahwa dalam memasuki abad ke-21 diperlukan cara-cara belajar baru untuk mengali pengetahuan secara cepat. Ada enam strategi untuk meraih percepatan belajar yaitu: motivating your mind, acquiring the information, searching out the meaning, triggering the memory, exhibiting what you now, and reflecting on how you have learned. Untuk mewujudkan diri dan siswa sebagai pembelajar yang efektif dalam memanfaatkan multimedia interaktif di era disrupsi, perlu memotivasi dan memusatkan pikiran pada hal-hal yang memiliki nilai manfaat bagi kehidupan (motivating your mind). Guru hendaknya mencari informasi mengenai multimedia interaktif dan bukan hanya menunggu fasilitas dari pemerintah (acquiring the information), pahami setiap informasi dengan kritis, gali maknanya, dan jangan terprokasi dan timbang-timbang baik dan buruknya, jangan asal copy dan paste (searching out the meaning), kaitkan pengetahuan dan informasi baru dengan pengalaman siswa, bandingkan, selerasikan dan internalisasikan secara bijak untuk menetapkan keputusan, ujaran dan sikap yang lebih bermakna (triggering the memory), selanjutnya lihat realitas yang ada supaya ada harmonisasi diri dan lingkungan, agar keberadaan kita tidak tercabut dalam kehidupan kemasyarakatan (exhibiting what you know) dan yang terakhir adalah merefleksikan manfaat, keuntungan dan dampak dari pengalaman belajar yang diperoleh (reflecting on how you have learned). Bagi peserta didik maupun guru akan termotivasi jika pengalaman belajar adalah memberi manfaat, keuntungan dan dampak yang lebih baik.

Penggunaan multimedia interaktif sebagai efek dari era disruptif memberikan manfaat yang besar terhadap kegiatan pembelajaran. Dengan adanya multimedia interaktif, guru dimudahkan dalam memberikan informasi mengenai pembelajaran serta siswa akan lebih termotivasi dalam mengikuti pembelajaran. Hal tersebut diungkapkan pula pada hasil penelitian Dwi Yuniasih Saputri (2018) menjelaskan bahwa penggunaan multimedia interaktif berbasis game dapat meningkatkan kemampuan kognitif siswa dengan hasil pengujian effect size pada siswa kelas $\mathrm{V}$ sekolah dasar.

Dengan langkah dan proses penggunaan multimedia interaktif yang tepat, menggunakan multimedia interaktif sebagai media pesan akan merangsang pemikiran, perasaan, kekhawatiran dan keinginan siswa sehingga dapat mendorong proses pembelajaran lebih interaktif dan komunikatif serta dapat meningkatkan pengalaman belajar siswa menjadi lebih konkret. Hasil penelitian mengungkapkan bahwa multimedia interaktif dianggap penting dalam upaya pemanfaatan IT pada pembelajaran di era disrupsi akan tetapi masih banyak guru yang belum sadar dan menerapkannya. 


\section{SIMPULAN}

Era disrupsi diartikan sebagai masa di mana bermunculan banyak sekali inovasiinovasi yang tidak terlihat, tidak disadari oleh organisasi mapan sehingga mengganggu jalannya aktivitas tatanan sistem lama atau bahkan menghancurkan sistem lama tersebut. Dunia pendidikan juga harus siap dalam menghadapi era disrupsi ini khususnya dalam era teknologi yang semakin maju. Cara sekolah dalam menghadapi era disruptive ini adalah perlu adanya pemimpin dengan disruptive mindset. Diperlukan orang-orang untuk membaca tanda-tanda zaman, yang mampu membaca realitas dan tidak hidup dalam perangkap masa lalu.

Salah satu upaya dalam pengembangan pembelajaran berbasis era disupsi khususnya di sekolah dasar adalah penggunaan multimedia interaktif. Dengan langkah dan proses penggunaan multimedia interaktif yang tepat, menggunakan multimedia interaktif sebagai media pesan akan merangsang pemikiran, perasaan, kekhawatiran dan keinginan siswa sehingga dapat mendorong proses pembelajaran lebih interaktif dan komunikatif serta dapat meningkatkan pengalaman belajar siswa menjadi lebih konkret. Hasil penelitian mengungkapkan bahwa multimedia interaktif dianggap penting dalam upaya pemanfaatan IT pada pembelajaran di era disrupsi akan tetapi masih banyak guru yang belum sadar dan menerapkannya.

\section{DAFTAR PUSTAKA}

Anitah, Sri. (2012). Media Pembelajaran. Surakarta: Yuma Pressindo.

Atmawarni. (2011). Penggunaan Multimedia Interaktif Guna Menciptakan Pembelajaran yang Inovatif di Sekolah. Jurnal IImu Sosial Fakultas ISIPOL Vol. 4, Nomor 1. UMA. ISSN: 2085-0328.

Colin Rose and Malcolm J. Nicholl. (1997). Accelerated Learning for The $21^{\text {st }}$ Century. New York: Dell Publishing.

Iskandar, Mustoha. (2017). Disruption Era: Opportunity or Threat bagi Institusi Unversitas?. Disampaikan pada Kuliah Umum dalam Rangka Perkuliahan Tahun Ajaran 2017/ 2018. Banjarmasin: Program Pasca Sarjana Lambung Mangkurat.

Khasali, Rhenald. (2017). Meluruskan Pemahaman Soal Disruption. Diakses di https://ekonomi.kompas.com/read/2017/05/05/073000626/meluruskan.pemaham an.soal.disruption Pada Tanggal 27 Juli 2018.

Nandi. (2006). Penggunaan Multimedia Interaktif dalam Pembelajaran Geografi di Persekolahan. Jurnal "GEA" Jurusan Pendidikan Geografi Vol. 6, No. 1, April 2006.

Saputri, Dwi Yuniasih. (2018). Pengembangan Multimedia Interaktif Berbasis Game untuk Meningkatkan Kemampuan Kognitif Kelas V Sekolah Dasar. Tesis. Surakarta: Universitas Sebelas Maret.

Smaldino, Sharon E, dkk. (2011). Instructional Technology and Media for Learning: Teknologi Pembelajaran dan Media untuk Belajar. Jakarta: Kencana.

UU No. 20 Tahun 2003 tentang Sistem Pendidikan Nasional 